\title{
A study of anti-poly(ADP-ribose) antibodies and an anti-DNA antibody idiotype and other immunological abnormalities in lupus family members
}

\author{
C DUDENEY, ${ }^{1}$ Y SHOENFELD ${ }^{2}$ J RAUCH ${ }^{3}$ M JONES,${ }^{1}$ \\ C MACKWORTH YOUNG,${ }^{4}$ M TAVASSOLI, ${ }^{5}$ S SHALL, ${ }^{5}$ AND \\ D A ISENBERG ${ }^{1}$
}

From the ${ }^{\prime}$ Department of Rheumatology, University College Hospital/Middlesex, London; the ${ }^{2}$ Department of Medicine D, Soroka Hospital, Beer Sheva, Israel; the ${ }^{3}$ Department of Rheumatology, Montreal General O Hospital, Canada; the ${ }^{4}$ Department of Haematology/Onocology, Tufts, Boston; and the ${ }^{5}$ Department of ${ }^{N}$ Molecular and Cell Biology, University of Sussex.

SUMMARY The genetic background of systemic lupus erythematosus (SLE) has been reexamined in a study of the serum of 31 lupus patients and 80 asymptomatic first degree relatives by measuring a common, cross reacting anti-DNA antibody idiotype designated 134, antibodies to poly(ADP-ribose), serum $\mathrm{C} 3$, circulating immune complexes, and antinuclear antibodies (ANA). Over $30 \%$ of the relatives had raised 134 and anti-poly(ADP-ribose) levels, and $9 \%$ had ANA titres $>1 / 20$. In contrast, only one relative had a low serum C3 level. These results confirm that immunogenetic abnormalities associated with the production of autoantibodies and particular idiotypes must exist amongst lupus relatives as well as the patients. The production of autoantibodies, however, is not necessarily matched to the clinical expression of SLE.

Key words: SLE, SLE immunogenetics, circulating immune complexes.

The precise aetiology of systemic lupus erythematosus (SLE) is unknown, but the pathogenesis is clearly dependent upon a complex interaction of trigger factors and hormonal influences, set against a background of genetic predisposition.

It has been shown that the prevalence of SLE varies between ethnic groups. A Hawaiian study reported prevalence rates ranging from 5.8 per 100000 among Caucasians to $24 \cdot 1$ per 100000 among ethnic Chinese, ${ }^{1}$ and other reports show lupus to be most common in black women. ${ }^{2}$

An individual's potential to develop lupus is dependent upon both inherited and environmental factors. ${ }^{3}$ Estes and Christian reported a positive family history in SLE in $4 \%$ of cases. ${ }^{4}$ The concord-

Accepted for publication 9 December 1985.

Correspondence to Dr D A Isenberg, Department of Rheumatology and Rehabilitation, Gower Street, London WC1E 6AU. ance rate of SLE in monozygotic twins, however, is $65 \% .^{5}$

Inherited complement deficiency states are also associated with SLE, notably a deficiency of $\mathrm{C} 2$ and the terminal sequence (C5-C9). ${ }^{6}$ A recent study $D$ showed that over $80 \%$ of Caucasian lupus patients had silent or null alleles of C4A or C4B (and in one N case C2) compared with only $40 \%$ of a matched normal group. ${ }^{7}$ HLA studies have most consistently 0 shown assocaitions with A1. B8, DR2, and DR $3,{ }^{8} \mathrm{\omega}$ and the frequency of the $\mathrm{Gm}$ allotype 1,$17 ; 5,6,13$ was shown to be substantially raised in black American lupus patients. ${ }^{9}$

The sera of asymptomatic relatives of lupus $\stackrel{\text { ? }}{+}$ patients have been shown to contain auto- $\frac{T}{T}$ antibodies ${ }^{10}$ and raised circulating immune complex $\underset{\mathbb{D}}{\stackrel{O}{0}}$

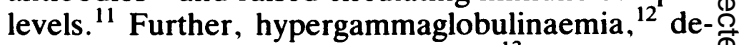

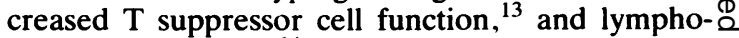
cytotoxic antibodies ${ }^{14}$ have also been found in some studies. 
In a previous study we detected the presence of two common cross reacting anti-DNA antibody idiotypes, designated $16 / 6$ and $32 / 15$, in lupus patients and their relatives. ${ }^{15}$ Raised $16 / 6$ and $32 / 15$ serum idiotype levels were found in $24 \%$ and $7 \%$ respectively of the relatives. The presence of these idiotypes, which were originally identified on hybridoma derived human monoclonal anti-DNA antibodies from different patients, implies that they are the products of genes present throughout the population.

In this study we have re-examined the sera of a large number of lupus patients and their relatives, looking for a variety of immunological abnormalities in order to re-evaluate the importance of the genetic component in SLE. Specifically, we have looked at antibodies against poly(adenosine diphosphate-ribose), which are found in SLE patients as frequently, if not more frequently, than antibódies against double stranded DNA. ${ }^{16}{ }^{17}$ Antipoly(ADP-ribose) antibodies were first discovered in the sera of SLE patients by Kanai et al, ${ }^{18}$ and these antibody levels have been shown to correlate well with disease activity. ${ }^{19}$

We have also looked for the presence of another anti-DNA antibody, idiotype 134. This idiotype differs from the idiotypes previously examined in that the antibody on which it was first identified binds strongly to double stranded DNA (dsDNA) in an enzyme linked immunosorbent assay (ELISA). ${ }^{19}$ In contrast, $16 / 6$ and $32 / 15$ bind to single stranded DNA (ssDNA) but show little binding to dsDNA. ${ }^{19}$

We have also examined the sera for circulating immune complex levels, serum $\mathrm{C} 3$ levels, and the presence of antinuclear antibodies by immunofluorescence on a $\mathrm{HEp}_{2}$ cell line.

\section{Patients and methods}

\section{PAT I ENTS}

Thirty one patients with SLE from 30 different families were studied. Twenty nine of these patients were female, and all patients, male and female, fulfilled four or more of the American Rheumatism Association's revised criteria for the classification of SLE. ${ }^{20}$ Sera from 80 of their healthy first degree relatives, 49 female and 31 male, were also included in the study. The age range of the relatives was $12-80$ years (mean \pm SD $45 \pm 19$ ). (The age was not recorded in a few cases). The 40 clinically healthy controls (28 female and 12 male) were healthy volunteers, blood bank donors, or people with soft tissue injuries only, who attended a rheumatology clinic. The age range of the controls was 23-87 years (mean age \pm SD $43 \cdot 8 \pm 19$ ). These controls were used to establish a normal range in the anti-poly (ADP- ribose) antibody assay and the 134 antibody assay. Over 100 healthy individuals were used to establish the range of $\mathrm{C} 3$ and immune complexes.

ANTI-POLY (ADP-RIBOSE) ANTIBODY ELISA A 96 well polystyrene ELISA plate (Immulon 2, Dynatech) was precoated with $50 \mu \mathrm{l}$ of poly-L-lysine (Sigma) $(50 \mu \mathrm{g} / \mathrm{ml}$ in distilled water $)$ and incubated for one hour at $37^{\circ} \mathrm{C}$. Each well was then washed three times with phosphate buffered saline (PBS) (Flow) before the addition of $50 \mu$ l of poly(ADPribose) $(10 \mu \mathrm{g} / \mathrm{ml})$ in PBS. The poly(ADP-ribose) was prepared as previously described. ${ }^{21}$ After incubation overnight at $4^{\circ} \mathrm{C}$ the plates were washed three times with PBS. They were blocked with $100 \mu \mathrm{l}$ of $2 \%$ casein (BDH) in PBS to prevent nonspecific binding, and after one hour's incubation at $37^{\circ} \mathrm{C}$ were washed three times with $\mathrm{PBS}-0 \cdot 1 \%$ Tween (PBS-T) (Sigma). Test serum samples were diluted $1 / 50$ in PBS-T and $50 \mu$ l aliquots were added to the wells in duplicate. A known high positive serum in quadruplicate and sera from eight healthy individuals were included on each plate.

After incubation for two hours at $4^{\circ} \mathrm{C}$ the plates were washed three times with PBS-T, and $50 \mu \mathrm{l}$ of alkaline phosphatase, conjugated goat antihuman polyvalent immunoglobulin (Sigma) diluted 1/350 in PBS-T $/ 0.5 \%$ casein was then added.

Incubation was carried out at $37^{\circ} \mathrm{C}$ for one hour, and after washing six times with PBS-T, $50 \mu \mathrm{l}$ of substrate, $p$-nitrophenyl phosphate disodium in $50 \mathrm{mM}$ carbonate buffer, $\mathrm{pH} 9 \cdot 5$, containing $2 \mathrm{mM}$ $\mathrm{Mg}^{2+}$, was added to the plate.

The reaction was allowed to proceed for one hour at $37^{\circ} \mathrm{C}$, and the resulting colour change was recorded at an absorbance of $410 \mathrm{~nm}$ with a Dynatech MR600 ELISA reader. The values obtained were expressed as a percentage of the known high positive value.

\section{ANTIBODY IDIOTYPE ELISA}

The human monoclonal anti-DNA antibody 134 was produced as described elsewhere. ${ }^{22}$ Idiotype 134 bound to both dsDNA and ssDNA, though more strongly to the former. The polyclonal, rabbit anti134 was derived by a previously described method. ${ }^{23}$

The test serum samples were diluted $1 / 1000$ in borate buffer, and $100 \mu \mathrm{l}$ aliquots were incubated in duplicate in the wells of a 96 well polystyrene ELISA plate (Immulon 2, Dynatech) overnight at $4^{\circ} \mathrm{C}$. A known high positive serum (in quadruplicate) and sera from eight normal healthy controls were included on each plate.

The plates were washed three times in PBS (Flow) containing 1\% Tween (Sigma) and three times in PBS, and after a two hour incubation at room temperature with $100 \mu \mathrm{l}$ of rabbit anti-134 
idiotype at a dilution of $1 / 10000$ they were washed again (as above) and incubated overnight at room temperature with $100 \mu \mathrm{l}$ of alkaline phosphatase, conjugated goat antirabbit immunoglobulin (Sigma) diluted $1 / 350$ in PBS-T. After the same washing procedure $100 \mu$ l of substrate. $p$-nitrophenyl phosphate disodium in $50 \mathrm{mM}$ carbonate buffer. $\mathrm{pH} 9.5$. containing $2 \mathrm{mM} \mathrm{Mg}^{2+}$, was added to the plate.

The reaction was allowed to proceed for one hour at $37^{\circ} \mathrm{C}$, and the resultant colour change was recorded at an absorbance of $410 \mathrm{~nm}$ with a Dynatech MR600 ELISA reader. The values obtained were expressed as a percentage of the known high positive value.

DNA ANTIBODY MEASUREMENT BY ELISA

The majority of the sera with raised 134 idiotype levels were also tested by an ELISA method for DNA binding by a modification of a previously described method. ${ }^{15}$ In brief: 96 well polystyrene plates (Immulon, Dynatech) were precoated with $50 \mu \mathrm{l}$ of poly-L-lysine (Sigma) and incubated for one hour at $37^{\circ} \mathrm{C}$. After washing with phosphate buffered saline the plates were coated with dsDNA $10 \mu \mathrm{g} / \mathrm{ml}$ or ssDNA $5 \mu \mathrm{g} / \mathrm{ml}$. The dsDNA was prepared by treating calf thymus DNA (Sigma) with S1 nuclease (Sigma) for 30 minutes at $37^{\circ} \mathrm{C}$. The ssDNA was prepared by boiling calf thymus DNA for 10 minutes and cooling on ice for 15 minutes. The plates were treated with $2 \%$ casein $(\mathrm{BDH})$ in PBS to prevent non-specific binding, and after washing $50 \mu \mathrm{l}$ test serum samples diluted $1 / 200$ in PBS-T were added in duplicate. A known high positive serum and sera from eight healthy individuals were included on each plate. The ELISA assay then proceeded as described previously, ${ }^{15}$ and the values obtained were expressed as a percentage of the known high positive value. The upper limits of normal on the 40 healthy controls were set at IgM ssDNA antibodies $10 \%$; IgG ssDNA antibodies $20 \%$; IgM dsDNA antibodies $7.5 \%$; IgG dsDNA antibodies $12 \%$. Each figure is greater than the mean plus three standard deviations.

Serum C3 was measured by radial immunodiffusion as described elsewhere. ${ }^{24}$ Circulating immune complexes were measured by polyethylene glycol precipitation using the method of Creighton et $a l^{25}$ as modified by Poulton and colleagues. ${ }^{26}$ The presence of antinuclear antibodies (ANA) was tested with serial dilutions of serum on a human epithelial cell line $\left(\mathrm{HEp}_{2}\right)$. Fluorescence at a titre $>1 / 20$ was considered to be positive. The five highest 134 idiotype binding sera in the patient and relative groups were tested for the presence of IgG, IgA, and IgM rheumatoid factor by a standard solid phase radioimmunoassay.

\section{Results}

Serum levels of anti-poly(ADP-ribose) antibodies were expressed as a percentage of the value for a known high positive individual, and the values in the 40 normal persons gave a mean of $16 \cdot 5$ (SD 7.4). The upper limit of normal was set at 32\% (> mean $+2 \mathrm{SD})$. Only one of the controls $(2.5 \%)$ exceeded this. In contrast. 18 of the lupus patients $(58 \%)$ and $\overrightarrow{0}$ $35(44 \%)$ of the relatives were found to have raised levels of anti-poly(ADP-ribose) antibodies (see Fig. $1)$. When the median group values were compared there were significant differences between both patient and relative groups and the normal popu- $\frac{\vec{c}}{\mathrm{c}}$ lation $(p<0 \cdot 0001$. Mann-Whitney $U$ test $)$. The or difference between patient and relative groups did not reach significance.

Serum levels of the 134 idiotype in the 40 healthy 윽 controls gave a mean percentage value (compared with the value for the known high positive indi- $\subseteq$ vidual) of $10.5 \% \pm 10 \%$. Fourteen of the 31 patients $\vec{D}$ $(45 \%)$ and 24 of the 80 relatives $(30 \%)$ had $134 \overrightarrow{0}$ idiotype levels in excess of the upper limit of normal o also set at $32 \%(>$ mean $+2 \mathrm{SD})$. Only one of the controls exceeded this value (Fig. 2) A comparison of the median group values of the three groups again

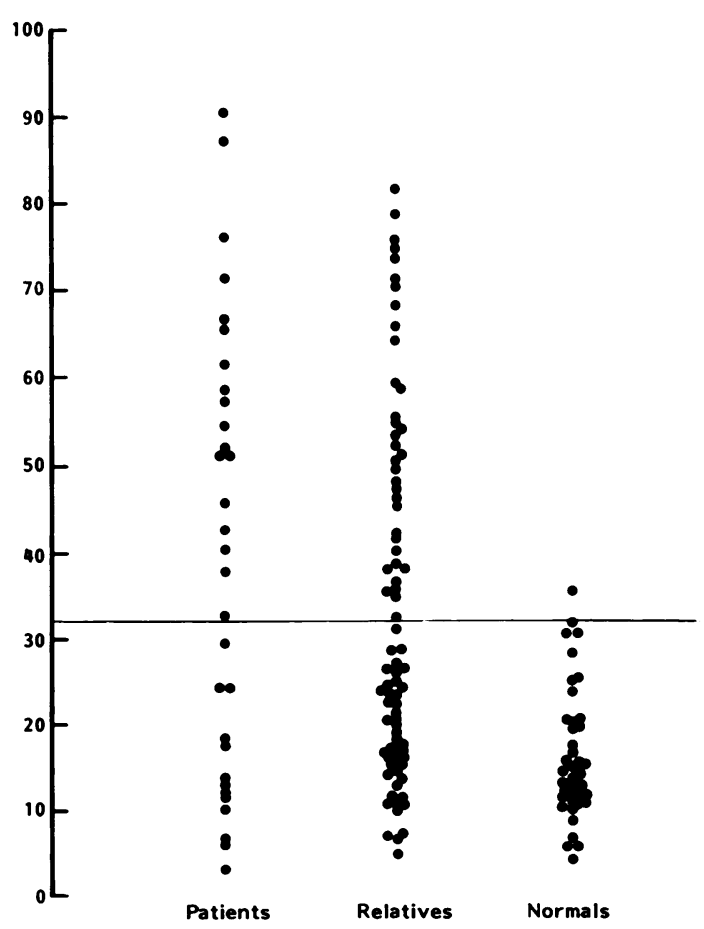

Fig. 1 Serum poly(ADP-ribose) levels in patients, relatives, and normals. 


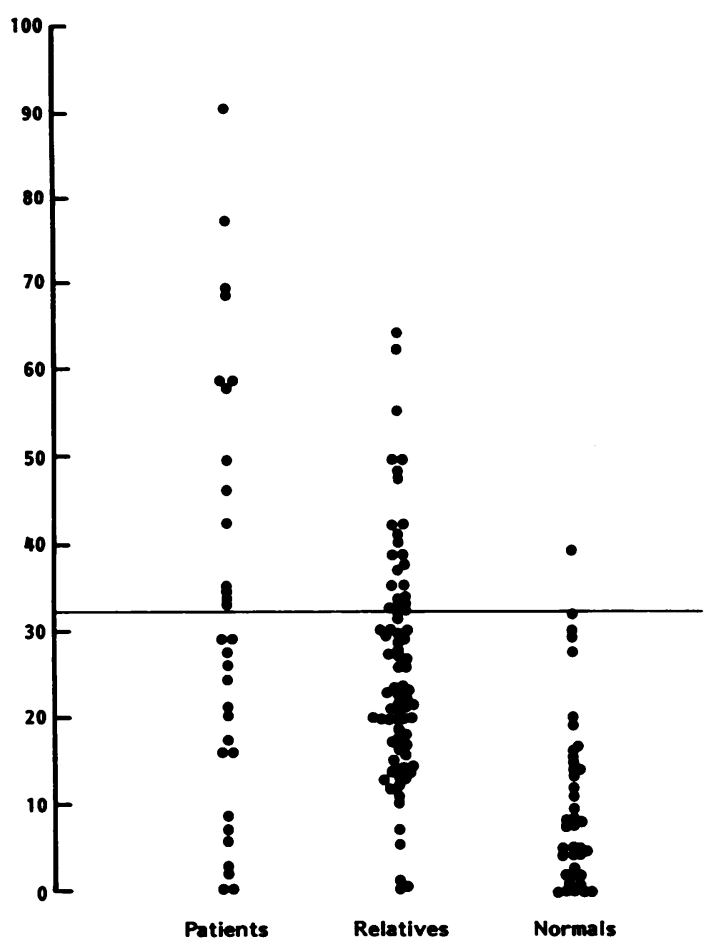

Fig. 2 Serum 134 idiotype levels in patients, relatives, and normals.

showed a statistically significant difference between both patient and relative groups and the normals $(\mathrm{p}<0.0001$, Mann-Whitney U test), but no difference between the patient and relative groups. The relatives with high 134 idiotype levels were confined to 10 families. In six of these families the index case also had a raised 134 idiotype level. One family was notable as the index case and five relatives had high levels. In two other families the index case and three relatives had raised 134 idiotype levels.

Of the 11 patients and 20 relatives with high 134 idiotype levels who were tested for anti-DNA antibodies, nine of the patients, but only five of the relatives, had raised levels of $\mathrm{IgG} / \mathrm{IgM}$ antibodies to ss/dsDNA. The difference was statistically significant $\left(p<0 \cdot 01, \chi^{2}\right.$ analysis $)$.

Circulating immune complex levels were raised in $13(46 \%)$ of the lupus patients but in only seven $(10 \%)$ of the relatives (see Fig. 3). Only two lupus patients (both with very active disease) and one relative had low serum $\mathrm{C} 3$ levels. A positive ANA test with a titre $>1 / 20$ was found in $75 \%$ of the patients and $9 \%$ of the relatives. When the sera in the patient and relative groups with the highest

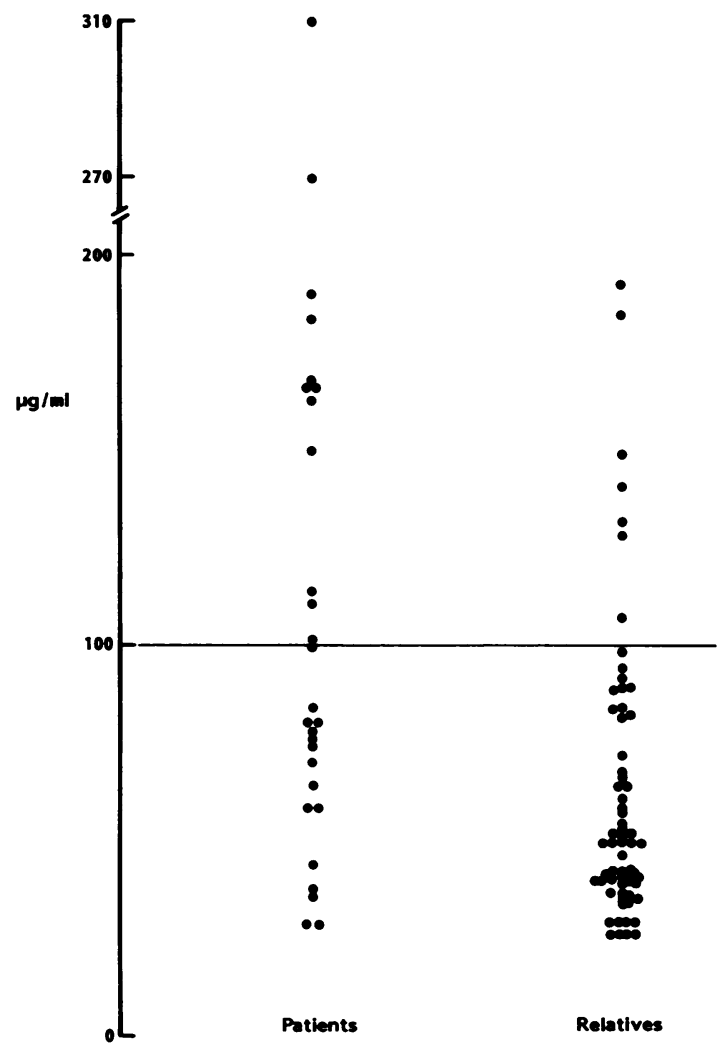

Fig. 3 Serum circulating immume complex levels in patients and relatives.

idiotype levels were tested for rheumatoid factor only one patient was found to have a moderately raised $\operatorname{IgA}$ level (data not shown).

\section{Discussion}

This study confirms that family members of lupus patients may express autoantibodies and idiotypes identified on autoantibodies without having the disease.

Previous reports have shown that anti-poly(ADPribose) antibodies show relative disease specificity and are rarely found in normal individuals. ${ }^{16} 17$ These studies used radioimmunoassays. In this study, using an ELISA, we have confirmed that healthy individuals do not express anti-poly(ADPribose) antibodies, though they are found in many SLE patients. More than $40 \%$ of healthy family members, however, also had raised levels.

In our previous report we examined idiotypes first identified on hybridoma derived monoclonal antissDNA antibodies and showed that these idiotypes 
$(16 / 6,32 / 15)$ were frequently found on antibodies in the serum of SLE patients and, less often, in their asymptomatic relatives. ${ }^{15}$ These original results are extended by the present report which describes the idiotype 134 . The 134 idiotype was originally identified with an ELISA on a hybridoma derived monoclonal antibody binding strongly to dsDNA, though a subsequent report of a radioimmunoassay showed strong binding to ssDNA. ${ }^{27}$ We have found the 134 idiotype in $45 \%$ of SLE patients and $30 \%$ of their asymptomatic relatives. These results are in concordance with a recent report which showed that the anti-DNA idiotype 3I, found in 7/8 SLE patients, was also found in $15 / 19$ relatives. ${ }^{28}$ (These values are slightly higher than the values for our idiotype.)

The presence of serum autoantibodies with the 134 idiotype in healthy relatives implies that it is not simply a pathogenic marker of SLE. The idiotype is clearly not confined to anti-dsDNA antibodies, but it is well recognised that idiotypes may be shared by antibody molecules with different antigen binding properties. ${ }^{29} 30$ Precisely which antibodies bear the 134 idiotype remains uncertain, though our results would indicate that they are not on rheumatoid factors. This idiotype, however, does mark a group of individuals, perhaps those in whom the idiotype is found on dsDNA antibodies more likely to have the disease, as shown by its presence in $45 \%$ of SLE patients. The expression of common idiotypes in SLE patients and their healthy family relatives may imply not so much a propensity to develop the disease as the inheritance of germ line immunoglobulin genes encoding for these relatively public idiotypes. ${ }^{31}$ An alternative explanation is that the presence of the idiotype represents a dominant immunoglobulin gene rearrangement both in the patients and their relatives. Clonal analysis of SLE B lymphocytes for dominant immunoglobulin gene rearrangements at the DNA level could be used to confirm this. ${ }^{32}$

It would be interesting to look at the 134 idiotype and anti-poly(ADP-ribose) antibody levels in patients suffering from inflammatory diseases, in which anti-DNA or anti-poly(ADP-ribose) antibodies are present due to an infection such as malaria or leprosy, and compare their idiotype and anti-poly(ADP ribose) antibody levels with those of their uninfected first degree relatives. If both relatives and patients were 134 positive then the hypothesis of restricted V regions in SLE might not be accurate, but if the relatives were 134 negative (and the patients 134 positive) this might suggest that the expression of idiotype $\mathrm{V}$ genes is related not just to the germ line but to some other factor peculiar to the stimulus for anti-DNA antibodies.
Additional experiments, such as assaying the pokeweed mitogen stimulated peripheral blood mononuclear cell supernatants in seronegative relatives or normals, would give some clue as to the origin of this idiotype

Approaches similar to those employed in tracing the idiotype through the family could be used to trace the development of anti-poly(ADP-ribose) antibodies. This might give some clue as to the stimulus for their production. A vertical inheritance through one parent to one of many children, for example, would provide evidence against an infectious aetiology.

In this study very few patients or relatives had low C3 levels. This may reflect the fact that many of the patients, who were attending outpatient clinics, had restricted disease activity. In addition, the bias in our departments is towards patients with rheumatological or haematological disease, or both, rather than towards those with renal involvement, which is more commonly associated with low $\mathrm{C} 3$ levels.

Forty six per cent of the SLE patients had raised circulating immune complex (CIC) levels, but only $10 \%$ of relatives had values above the normal limit. This is in contrast with the work of Elkon et al, who showed that $26 \%$ of relatives had raised CIC levels. ${ }^{11}$ This may reflect the different CIC assays used.

Antinuclear antibodies (ANA) as previously reviewed by Walport $e t a l^{8}$ have been found to occur in anything from 4 to $60 \%$ of lupus relatives. Our findings show that only $9 \%$ of relatives had antinuclear antibodies, which is at the lower end of the range and a little lower than the $17 \%$ we noted in our previous study. ${ }^{15}$ One puzzling result was the low percentage of ANA positive relatives who had anti-poly(ADP-ribose) antibodies, since the nucleus of epithelial cells $\left(\mathrm{HEp}_{2}\right)$ does contain poly(ADPribose). ${ }^{33}$ The explanation may relate to the sensitivities of the test systems used.

The above observations taken together with the other reports cited confirm that healthy family members of SLE patients often have serological abnormalities suggestive of the disease, but without any clinical evidence of involvement. This reemphasises that although the genetic component of lupus is obviously important, it is not the only arbiter of disease expression.

\section{References}

1 Serdula M K, Rhoades G G. Frequency of systemic lupus erythematosus in different ethnic groups in Hawaii. Arthritis Rheum 1979; 22: 339-50.

2 Siegel M, Holley H L, Lee S L. Epidemiologic studies on systemic lupus erythematosus. Comparative data for New York $\sigma$ City and Jefferson County, Alabama, 1956-1965. Arthritis Rheum 1970; 13: 802-11. 
3 Shoenfeld Y S, Schwartz R S. Genetic and immunological factors in autoimmune diseases. $N$ Engl $J$ Med 1984; 311: 1019-29.

4 Estes D. Christian C L. The natural history of systemic lupus erythematosus by prospective analysis. Medicine (Baltimore) 1971: 50: 85-95.

5 Block S R, Winfield J B. Lockshin M D, D'Angelo W A, Christian C L. Studies of twins with svstemic lupus erythematosus. Am J Med 1975; 59: 533-52.

6 Rynes R I. Inherited complement deficiency states and SLE. Clin Rheum Dis 1982; 8: 29-47.

7 Fielder A H L, Walport M J, Batchelor J R. et al. Family study of the major histocompatibility complex in patients with systemic lupus erythematosus: importance of null alleles of $\mathrm{C4A}$ and C4B in determining disease susceptibility. $\mathrm{Br} \mathrm{Med} \mathrm{J} \mathrm{1983;}$ 286: 425-8.

8 Walport M J, Black C M, Batchelor J R. The immunogenetics of systemic lupus erythematosus. Clin Rheum Dis 1982; 8: 3-21.

9 Frederick J A. Pandey J P, Chen Z, Fudenberg H H. Ainsworth $\mathrm{S} \mathrm{K}$, Dobson R L. Gm allotypes in blacks with systemic lupus erythematosus. Hum Immunol 1983: 8: 177-81.

10 Lehman T J A. Curd J G. Zvaifler N J. Hanson V. The association of antinuclear antibodies, antilymphocyte antibodies and $\mathrm{C} 4$ activation among the relatives of children with systemic lupus erythematosus. Arthritis Rheum 1982; 25: 556-61.

11 Elkon K B, Walport M J, Rynes R I, Black C M, Batchelor J R, Hughes G R V. Circulating C1q binding complexes in relatives of patients with systemic lupus erythematosus. Arthritis Rheum 1983; 26: 921-4.

12 Moreteo O G, Franklin E C, McEwen C, Phythyon J, Tanner $M$. Studies of relatives of patients with systemic lupus erythematosus. Arthritis Rheum 1961; 4: 356-63.

13 Miller K B, Schwartz R S. Familial abnormalities of suppressorcell function in systemic lupus erythematosus. $N$ Engl J Med 1979; 301: 803-9.

14 Messner R P, De Horatius R, Ferrone S. Lymphocytotoxic antibodies in systemic lupus erythematosus patients and their relatives: reactivity with the HLA antigenic molecular complex. Arthritis Rheum 1980; 23: 265-72.

15 Isenberg D A, Shoenfeld Y S, Walport M J, et al. Detection of cross-reactive anti-DNA antibody idiotypes in the serum of lupus patients and their relatives. Arthritis Rheum 1985; 28: 999-1007.

16 Morrow W J W, Isenberg D A, Parry H F, et al. Studies on autoantibodies to poly(adenosine diphosphate-ribose) in SLE and other autoimmune diseases. Ann Rheum Dis 1982; 41: 396-402.

17 Clayton A L, Bernstein R M. Tavassoli M, et al. Measurement of antibody to poly(adenosine diphosphate-ribose): its diagnostic value in systemic lupus erythematosus. Clin Exp Immunol 1984; 56: $263-71$.

18 Kanai $Y$, Kawaminami $Y$, Miwa M, et al. Naturally occurring antibodies to poly(ADP-ribose) in patients with systemic lupus erythematosus. Nature 1977; 265: 175-7.

19 Shoenfeld Y, Rauch J. Massicotte H, et al. Polyspecificity of monoclonal lupus autoantibodies produced by human-human hybridomas. $N$ Engl J Med 1983: 308: 414-20.

20 Tan E M, Cohen A S, Fries J F, et al. The 1982 revised criteria for the classification of systemic lupus erythematosus. Arthritis Rheum 1982; 25: 1271-7.

21 Okolie E E, Shall S. The significance of antibodies to poly(ADP-ribose) in patients with systemic lupus erythematosus. Clin Exp Immunol 1979; 36: 151-64.

22 Shoenfeld Y S. Hsu-Lin S C. Gabriels J E, et al. Production of autoantibodies by human-human hybridomas. J Clin Invest 1982; 70: 205-8.

23 Shoenfeld Y S, Isenberg D A, Rauch J, Madaio M P, Stollar B D, Schwartz R S. Idiotypic cross-reactions of monoclonal human lupus autoantibodies. $J$ Exp Med 1983; 158: 718-30.

24 Mancini G, Carbonara A O. Heremans J F. Immunochemical quantification of antigens by single radial immunodiffusion. Immunochemistry 1965; 2: 235-54.

25 Creighton W D, Lambert P M. Miescher P A. Detection of antibodies and soluble antigen-antibody complexes by precipitation with polyethylene glycol. J Immunol 1973; 3: 1219 27.

26 Poulton T A. Crowther M E. Hay F C. Nineham L J. Immune complexes in ovarian cancer. Lancet 1978; ii: 72-3.

27 Rauch J. Massicotte H, Wild J, Tannenbaum H. Sensitive solid phase radioimmunoassay for the detection of anti-DNA autoantibodies. J Rheumatol 1985; 12: 482-6.

28 Halpern R, Davidson A, Lazo A, Lahita R, Solomon G, Diamond B. Familial SLE-presence of a cross reactive idiotype in healthy family members. J Clin Invest 1985; 76: 731-6.

29 Karol R, Reichlin M, Noble R W. Idiotypic cross-reactivity between antibodies of different specificities. J Exp Med 1978; 148: 1488-97.

30 Hiernaux J, Bona C A. Shared idiotypes among monoclonal antibodies specific for different immuno dominant sugars of lipopolysaccharide of different gram-negative bacteria. Proc Natl Acad Sci USA 1982; 79: 1616-20.

31 Rajewsky K. Takemori T. Genetics, expression and function of idiotypes. Ann Rev Immunol 1983; 1: 569-607.

32 Theofilopoulos A N, Balderas R S. Gozesy Y, et al. Association of $1 \mathrm{pr}$ gene with graft-vs-host disease like syndrome. J Exp Med 1985; 162: 1-18.

33 Kidwell W R, Mage M G. Changes in poly(adenosine diphosphate-ribose) and poly(adenosine diphosphate-ribose) polymerase in synchronous He La cells. Biochemistry 1976; 15: 1213-7. 